\title{
EDITORIAL
}

\section{A special issue devoted to STEM CELLS}

Our Biological Research Journal of the Society of Biology of Chile is definitely one of the scientific publications of experimental biology in Latin America with greatest impact internationally. Recently our ISI Impact Factor increased significantly, to 1.17 .

With the purpose of improving the visibility of Biological Research, the Society of Biology of Chile obtained a grant from the National Commission of Science and Technology (CONICYT), FP Project \# 11021-2012 entitled "Strategies to increase the visibility of Biological Research". In this project the strategies chosen to accomplish greater visibility were: the inclusion in social networks (Twitter and Facebook), Google AdWords and dissemination by publishing a special issue devoted to a focal topic. This latter strategy has generated this special issue of Biological Research dedicated to stem cells. For this issue we invited renowned international and national scientists who are actively working in research on basic and applied biological aspects of biomedicine of stem cells. To all of them we extend our sincere thanks. Dr. Alejandro Erices participated in the preparation of this special issue; so we appreciate his initial your collaboration in the editorial work.

The 12 articles contained in this special number address a broad range of issues, from the general aspects of stem cells, through basic biological aspects of different types of stem cells including cancer stem cells, and covering topics on the application of stem cells in human disease therapies, and finally a discussion of bioethical aspects of basic and applied research on human stem cells. The contributions of the invited scientists are:

1. The group of Professor Carlo Redi, of the Fondazione IRCCS, Pavia, Italy, with an article that provides an overview of biological and applied in therapy of stem cells.

2. The group of Dr. M. Sogayar, of the Chemistry Institute, Dept of Biochemistry, University of São Paulo, Brazil, covering the topic of stem cells in embryonic skin development.

3. The group of Dr. V. Palma, of the Faculty of Sciences, University of Chile, covering the subject of Sonic Hedgehog in cancer stem cells and its novel link with autophagy.

4. The group of Dr. E. Rodríguez, of the Institute of Anatomy, Histology and Pathology of the Austral University of Chile addresses the relationship of neural stem cells to abnormal neurogenesis and hydrocephalus.
5. The group of Dr. F. Nualart, of the Faculty of Biological Sciences, University of Concepción, Chile, addresses the problem of typical and atypical stem cells In the brain, in relation to Vitamin C and its effects in neuropathology.

6. Drs. F. Rivera and Ludwig Aigner of The Institute of Molecular Regenerative Medicine, Paracelsus Medical University, Austria, address the topic of adult mesenchymal stem cell therapy for myelin repair in Multiple Sclerosis.

7. The group of Dr. F. Figueroa, of the Faculty of Medicine, University of the Andes, Chile, makes a critical review of mesenchymal stem cell treatment for autoimmune diseases.

8. The group of Dr. J. P. Rodríguez of the Institute of Nutrition and Food Technology, University of Chile addresses the problem of the differentiation of mesenchymal stem cells and the improvement of bone marrow adipogenesis in osteoporosis.

9. The group of Dr. P. Conget, of the Institute of Sciences, Faculty of Medicine, Clínica Alemana-Universidad del Desarrollo, Chile, addresses the issue of stem cell mesenchymal transplantation as a strategy for the treatment of diabetic nephropathy.

10. The group of Dr. Castellón, of the Institute od Biomedical Sciences, Faculty of Medicine, University of Chile, addresses biological aspects of cancer stem cells isolated from prostate carcinomas.

11. The group of Dr. F. Barriga, of the Department of Pediatrics and Hematology Oncology, Faculty of Medicine, Catholic University of Chile, reviews the situation and prospects of the clinical use of hematopoietic stem cell transplantation.

12. Drs. M. J. Santos and P. Ventura-Juncá of the Faculties of Biology Sciences and Medicine at the Pontifical Catholic University of Chile address the bioethical aspects of basic research and medical applications of human stem cells.

We are confident that the quality of these various articles contained in this special issue of Biological Research will cause them be read worldwide and cited nationally and internationally, thus helping to improve visibility and the impact factor of our Biological Research journal.

MANuEl J. SANTOS, MD, PHD Editor Biological Research

PATRICIO OJEDA, PHD President Society of Biology of Chile 